\title{
Congenital diaphragmatic hernia in the older child
}

\author{
P D BOOKER, P W D MEERSTADT, AND G H BUSH
}

\author{
Alder Hey Childrens Hospital, Liverpool
}

SUMMARY Five children aged between 9 months and 7 years were admitted to hospital each with an unsuspected congenital diaphragmatic hernia. In 4 the diagnosis was pneumonia with a secondary pleural effusion or lung abscess. Initial investigations were unhelpful to the admitting physician; two of the children had had a previous chest $x$-ray which was normal. For 3 children the correct diagnosis was only made at necrospy. It is suggested that the possibility of a congenital diaphragmatic hernia be considered in any patient who has an indefinable diaphragm and cystic lesion on his chest $x$-ray film. Barium studies with the patient in Trendelenburg's position are of value in excluding the presence of bowel in the chest.

A congenital diaphragmatic hernia is a rare condition which usually presents in the first few days of life. At this age the clinical and radiological features should make the diagnosis obvious. In older children and adults however, the diagnosis may be more difficult, and is often made only at necropsy. ${ }^{1}$ Strangulation of bowel may occur within one of these herniae and good results from surgical intervention depend on prompt diagnosis. After the death at this hospital of an infant who had an unsuspected hernia, the records of other children who had died from this eminently treatable condition were examined. Their clinical features, radiological findings, and other investigations were reviewed in order to determine any points that could have led to an earlier diagnosis.

\section{Patients and methods}

There were 4 deaths secondary to congenital diaphragmatic herniae in children aged between 3 months and 10 years in England and Wales in the two years 1976 and 1977. Copies of their death certificates were obtained from the Office of Population Censuses and Surveys. Permission to include details of these patients was obtained from the appropriate hospital authorities and consultants. In

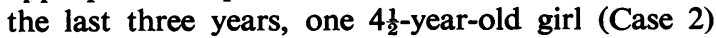
has been admitted to this hospital and been treated successfully.

Details of some of these cases are given below.

Case 1. A previously healthy 9-month-old boy was admitted to hospital 2 days after he had pulled a propped-up, folded, wooden playpen on to his chest and abdomen. He subsequently became unwell and listless, and he vomited twice. There were no external signs of trauma. Within 2 hours he had become progressively more toxic and developed grunting respirations. Air entry to the left chest was diminished. A chest $x$-ray film showed complete opacification of his left hemithorax with an ill-defined gas shadow in the left paravertebral region. The left diaphragm could not be identified. There was some displacement of the heart and mediastinum to the right. The initial diagnosis was a left pleural effusion and lung abscess secondary to a staphylococcal pneumonia. Nose and throat swabs, urine, blood culture, and cerebrospinal fluid (CSF) were screened for sepsis, and he was treated with antibiotics, intravenous fluids, and oxygen. Eleven hours after admission he had a generalised convulsion. His CSF was normal. His respiratory status continued to deteriorate so that shortly thereafter he required naso-tracheal intubation and institution of intermittent positive pressure ventilation (IPPV). A later chest $x$-ray film showed an air-fluid level in the left hemithorax. The possibility of an intrathoracic stomach secondary to a traumatic diaphragmatic hernia was considered. Barium introduced through a naso-gastric tube showed that the stomach was inferior and probably below the diaphragm (Fig. 1). A left pleural drain yielded a large amount of bloodstained, turbid, foul-smelling fluid. No organisms were seen on Gram stain and all initial cultures were negative. His general condition remained stable, although some upper abdominal fullness was noted. Treatment with antibiotics, supportive circulatory therapy, and IPPV continued. There was a small bleed from the rectum $\mathbf{5 5}$ hours after admission, and proctoscopy showed old blood in the rectum. 


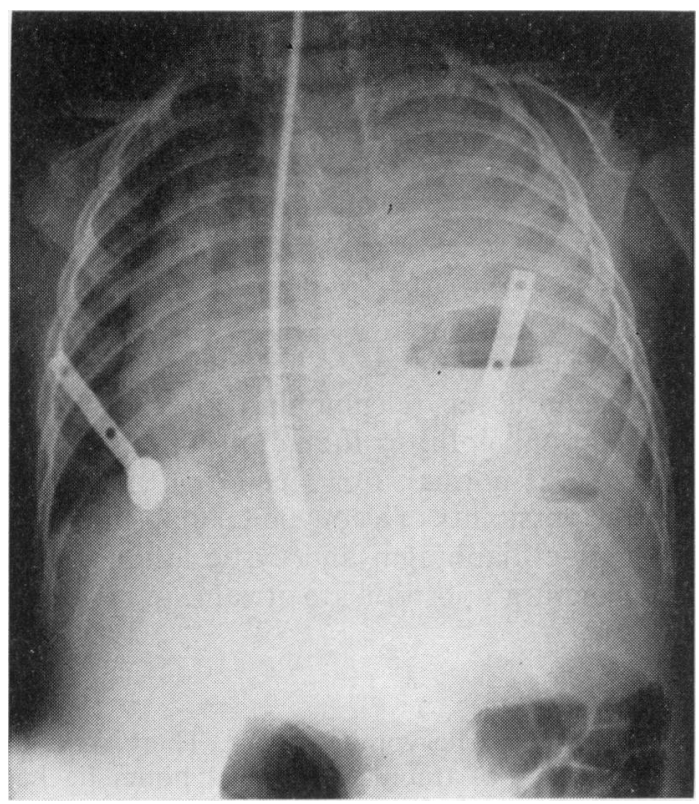

Fig. $1 X$-ray of chest and abdomen of Case 1. Note on left side the air-fluid level, indefinable diaphragm, and pleural effusion (with consequent tracheal deviation). Barium has been introduced via a tube into the lower oesophagus and stomach. ECG leads are in place.

Coagulation studies were normal. The child's pupils became fixed and dilated 60 hours after admission. The CSF was normal. Brain death was diagnosed 95 hours after admission. Necropsy showed that the left lung was compressed by a bloody effusion and there was an incarcerated diaphragmatic hernia which contained a necrotic segment of transverse colon. There was a foramen of Morgagni, $1 \mathrm{~cm}$ in diameter. The brain was softened and necrotic. No other abnormality was found.

Case 2. A previously healthy $4 \frac{1}{2}$-year-old girl was admitted to hospital with a 48-hour history of upper abdominal and left shoulder pain. She subsequently developed a cough and vomited on three occasions. She was found to be toxic, pyrexial, and tachypnoeic. Her trachea was deviated to the right and her left chest air-entry was diminished. A few coarse crepitations were heard in the left lower and right upper chest. A chest $x$-ray film showed an air-fluid level above some shadowing in the left lower zone (Fig. 2). Chest $x$-ray films taken at 14 and 35 months of age had been reported as normal. A provisional diagnosis was made of staphylococcal pneumonia with a lung abscess. She was treated with antibiotics, intravenous fluids, and oxygen. The next day she was

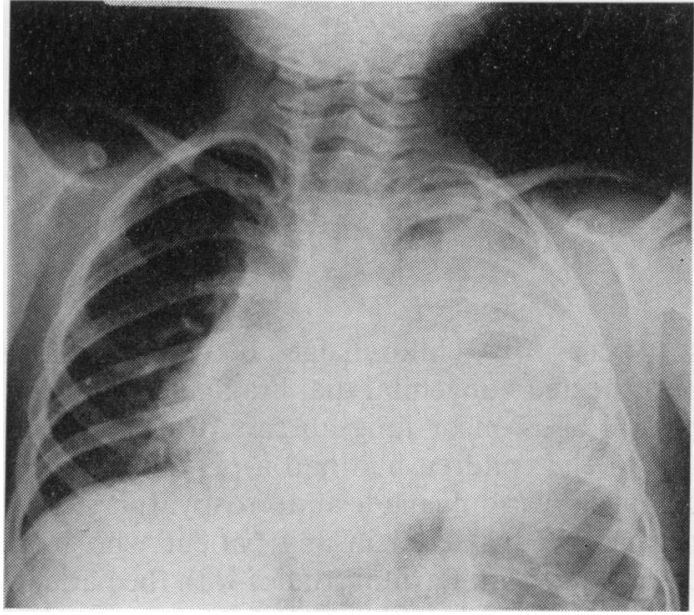

Fig. $2 X$-ray of chest and abdomen of Case 2. Note the air-fluid level and indefinable diaphragm in the left hemithorax. A left pleural drain is in situ.

more dyspnoeic and was noted to have a distended abdomen. The stony dullness at her left base was attributed to a secondary pleural effusion. A chest drain was inserted but only a small volume of blood-stained fluid was obtained. During the next 2 days her condition remained unchanged. She then developed an increasingly distended tender abdomen and vomited repeatedly. $X$-ray views of her abdomen showed marked small-bowel dilatation. A diagnosis was made of toxic ileus. Eight days after admission her condition deteriorated and she was found to have a left pneumothorax. A chest drain was inserted and dye injected through this drain was contained in a cavity in the left lower thorax. Proteus, Escherichia coli, and bacteroides were cultured from the pleural aspirate; for the first time the possibility of a diaphragmatic hernia was considered. A thoracotomy showed a loculated pleural cavity containing faeces, necrotic colon, and omentum. A bowel resection and colostomy were performed, and the diaphragmatic hiatus was repaired. Her postoperative recovery was normal.

Case 3. A 5-month-old girl with Down's syndrome was admitted to hospital with a 24-hour history of increasing respiratory distress and repeated vomiting. She was found to be drowsy and pyrexial with peripheral vasoconstriction and 'acidotic respiration'. There was bronchial breathing at the left base which was dull to percussion. No chest $x$-ray was requested. A diagnosis of lobar pneumonia was made and she was treated with intravenous fluids and 
antibiotics. Her condition improved. A chest $x$-ray film taken before discharge showed 'an anterior retrosternal diaphragmatic hernia containing loops of bowel'. (A chest $x$-ray taken 2 days before admission had been reported as normal.) Operative findings included a large central diaphragmatic hernia, malrotation, and Meckel's diverticulum. Her postoperative recovery was normal.

At age 7 years she was readmitted with vomiting and abdominal distension. A chest $x$-ray film showed distended loops of bowel in the right hemithorax. Although initially treated conservatively, subsequently a thoracotomy showed a right-sided foramen of Morgagni hernia containing a loop of gangrenous transverse colon. Her initial postoperative recovery was normal. However, on day 9 she went into acute left ventricular failure and died later that day.

Case 4. A $2 \frac{1}{2}$-year-old boy was admitted to hospital with a 24-hour history of frequent vomiting and a

Table 1 Presenting features in Cases 1-4

\begin{tabular}{|c|c|c|c|c|c|c|}
\hline \multirow[t]{2}{*}{ Presenting features } & \multicolumn{5}{|c|}{ Cases } & \multirow{2}{*}{$\begin{array}{l}\text { Present in } \\
\text { staphylococcal } \\
\text { pneumonia }\end{array}$} \\
\hline & $I$ & 2 & 3 & $3^{*}$ & 4 & \\
\hline $\begin{array}{l}\text { General malaise } \\
\text { Vomiting } \\
\text { Fever. } \\
\text { Respiratory distress } \\
\text { Cough } \\
\text { Cyanosis } \\
\text { Abdominal pain } \\
\text { Mediastinal shift } \\
\text { Chest signs of } \\
\text { pneumonia }\end{array}$ & $\begin{array}{l}\text { Yes } \\
\text { Yes } \\
\text { Yes } \\
\text { Yes } \\
\text { No } \\
\text { No } \\
\text { No } \\
\text { Yes }\end{array}$ & $\begin{array}{l}\text { Yes } \\
\text { Yes } \\
\text { Yes } \\
\text { Yes } \\
\text { Yes } \\
\text { No } \\
\text { Yes } \\
\text { Yes }\end{array}$ & $\begin{array}{l}\text { Yes } \\
\text { Yes } \\
\text { Yes } \\
\text { Yes } \\
\text { No } \\
\text { No } \\
\text { No } \\
\text { No }\end{array}$ & $\begin{array}{l}\text { Yes } \\
\text { Yes } \\
\text { No } \\
\text { No } \\
\text { No } \\
\text { No } \\
\text { Yes } \\
\text { Yes }\end{array}$ & $\begin{array}{l}\text { Yes } \\
\text { Yes } \\
\text { No } \\
\text { Yes } \\
\text { Yes } \\
\text { No } \\
\text { No } \\
\text { Yes }\end{array}$ & $\begin{array}{l}\text { Yes } \\
\text { Yes } \\
\text { Yes } \\
\text { Yes } \\
\text { Yes } \\
\text { Yes } \\
\text { Yes } \\
\text { Yes }\end{array}$ \\
\hline
\end{tabular}

*2nd admission. dry cough. He was febrile and slightly tachypnoeic. His trachea was deviated to the right and air entry to the left chest was diminished. A chest $x$-ray film was interpreted as showing a left lower lobe pneumonia and pleural effusion. Subsequently this $x$-ray was reported as 'a distended viscus in the left hemithorax displacing the mediastinum to the right'. He developed increasing respiratory distress and became cyanosed in air. He was treated conservatively and died 6 hours after admission. Necropsy showed a left-sided foramen of Bochdalek hernia containing a torted distended stomach, a small portion of colon, and the spleen.

Case 5. A 6-month-old girl was dead on arrival at the hospital. No history is available. Necropsy showed aspirated material in the trachea and both bronchi. There was a small longitudinal slit at the lower end of the oesophagus, and a small diaphragmatic hernia with the fundus of the stomach protruding into the thorax. Diagnosis: 'rupture of the oesophagus and congenital diaphragmatic hernia'.

Case 5. No details are available, other than those given in Table 3.

\section{Results}

The similarities in the presenting features of these children are summarised in Table 1. A comparison has been made with those symptoms and signs which may be seen in children with staphylococcal pneumonia.

Table 2 shows the results of the various investigations that were performed in each patient. A comparison has been made with those findings

Table 2 Results of investigations in Cases 1-4

\begin{tabular}{|c|c|c|c|c|c|c|}
\hline \multirow[t]{2}{*}{ Initial investigations } & \multicolumn{5}{|l|}{ Cases } & \multirow{2}{*}{$\begin{array}{l}\text { Present in staphylococcal } \\
\text { pneumonia }\end{array}$} \\
\hline & $I$ & 2 & 3 & $3^{*}$ & 4 & \\
\hline $\begin{array}{l}\text { Chest } x \text {-ray changes } \\
\text { White cell count (x 10\%/1) } \\
\text { Neutrophils ( } \%) \\
\text { Bacteriological cultures }\end{array}$ & $\begin{array}{l}\text { Left } \\
26 \\
61 \\
\text { Negative }\end{array}$ & $\begin{array}{l}\text { Left } \\
26 \\
83 \\
\text { Negative }\end{array}$ & $\begin{array}{l}\text { Centred } \\
22 \\
90 \\
\text { Negative }\end{array}$ & $\begin{array}{l}\text { Right } \\
20 \\
-\overline{N e g a t i v e}\end{array}$ & $\begin{array}{l}\text { Left } \\
\overline{-} \\
\text { Negative }\end{array}$ & $\begin{array}{l}\text { Right }>\text { left } \\
15-30 \\
60-90 \\
\text { Usually positive }\end{array}$ \\
\hline
\end{tabular}

*2nd admission.

Table 3 Site and contents of herniae in Cases 1-5

\begin{tabular}{|c|c|c|c|c|c|c|}
\hline & \multicolumn{6}{|l|}{ Cases } \\
\hline & 1 & 2 & 3 & $3^{*}$ & 4 & 5 \\
\hline $\begin{array}{l}\text { Hernial site } \\
\text { Hernial contents }\end{array}$ & $\begin{array}{l}\text { Foramen of } \\
\text { Morgagni (L) } \\
\text { Transverse colon }\end{array}$ & $\begin{array}{l}\text { Central } \\
\text { Colon. Omentum }\end{array}$ & $\begin{array}{l}\text { Central } \\
\text { Colon }\end{array}$ & $\begin{array}{l}\text { Foramen of } \\
\text { Morgagni (R) } \\
\text { Transverse colon }\end{array}$ & $\begin{array}{l}\text { Foramen of } \\
\text { Bochdalek (L) } \\
\text { Stomach. Colon. } \\
\text { Spleen }\end{array}$ & $\begin{array}{l}\text { Paraoesophageal } \\
\text { Stomach }\end{array}$ \\
\hline
\end{tabular}

*2nd admission. 
commonly encountered in children with staphylococcal pneumonia.

Table 3 shows the relationship between the site of herniation and the hernial contents.

\section{Discussion}

It is difficult to give an accurate figure for the incidence of congenital diaphragmatic herniae because some infants die undiagnosed in early neonatal life without necropsy; additionally some of them do not present until late childhood or adult life. ${ }^{2}$ In the British Perinatal Mortality Survey of $1958,0.95 \%$ of 1467 necropsied stillbirths and $1.9 \%$ of 1064 necropsied neonatal deaths were found to have diaphragmatic herniae. ${ }^{1}$ From these figures it has been estimated that diaphragmatic herniae occur in at least $1: 3600$ live births.

Congenital diaphragmatic herniae are classified according to their position (Fig. 3). $70-90 \%$ of these herniae are through the left diaphragm. ${ }^{13}$ Herniation most commonly occurs posterolaterally between the lumbar and costal muscle fibres of the diaphragm (the foramen of Bochdalek). Other herniae occur through defects in the central tendon, or anteriorly between the xiphisternal and costal muscle fibres of the diaphragm (the foramen of Morgagni). This latter type only accounts for about $1-2 \%$ of all congenital diaphragmatic herniae, ${ }^{4}$ despite their preponderance in this series.

Congenital diaphragmatic defects are not necessarily accompanied by herniation of abdominal viscera into the chest. If the neck of the sac is wide there may be free movement of viscera between the peritoneal and pleural cavities (as may have been the case in Case 3). In such patients the diagnosis may be made only if the chest $x$-ray film is taken with the patient in Trendelenburg's position. ${ }^{2}$ If the neck of the sac is narrow herniation may occur only when a critical intra-abdominal pressure is reached-for example, due to trauma (possibly relevant in Case 1), intestinal obstruction, or paralytic ileus. ${ }^{56}$ Thus, as shown in Cases 2 and 3, a previously normal chest $x$-ray film should not exclude the diagnosis of a congenital diaphragmatic hernia.

When an infant or child with diaphragmatic herniation is admitted to hospital the usual diagnosis is pneumonia with abscess formation, or a pleural effusion, or both of these. Other conditions-such as traumatic diaphragmatic hernia, pneumohaemothorax, hamartoma, emphysematous or hydatic cyst-need to be considered but are rare. Consequently, the differentiation from a staphylococcal pneumonia is likely to be the major diagnostic problem for the admitting physician.

A coexisting pneumonia secondary to aspiration or lung compression complicates the diagnostic dilemma as probably was the case in Cases 1,2 , and 3. Signs of overt intestinal obstruction generally are absent initially. ${ }^{3}$ Thus, the distinction from staphylococcal pneumonia may not always be possible on purely clinical grounds (Table 1 ).

Most of the investigations performed (Table 2) were unhelpful although in Case 2 the bacteriological culture from the pleural aspirate yielded a valuable clue (that is faecal organisms). It is usual in staphylococcal infections for a positive culture to be obtained unless treatment with antibiotics has been

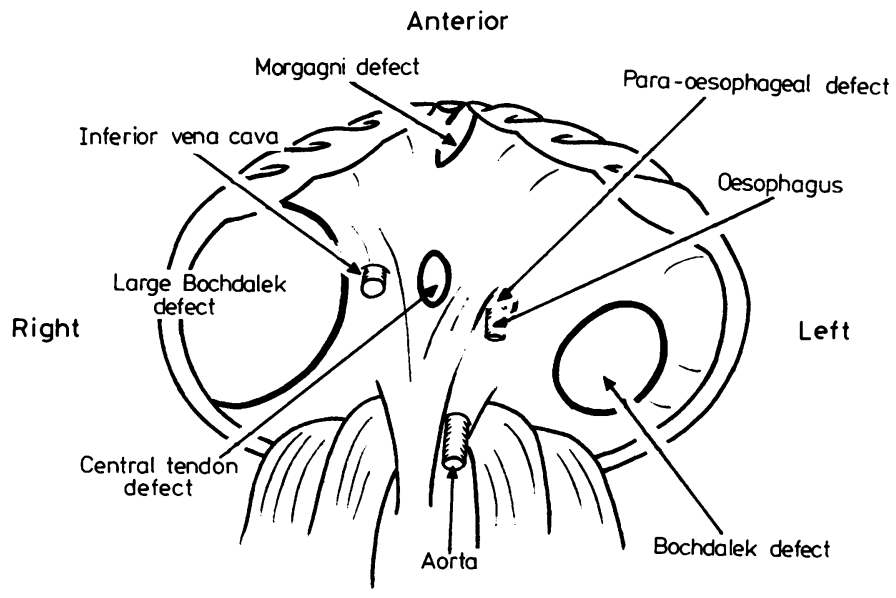

Fig. 3 The inferior aspect of the diaphragm showing the various sites of congenital diaphragmatic herniation. 
started. It should be noted that in each child in this series the initial culture was negative and therefore the initial diagnosis of staphylococcal pneumonia should have been questioned.

If a plain erect chest $x$-ray film is unhelpful, further views in Trendelenburg's position with a nasogastric tube in place may be of benefit. Contrary to previous authors ${ }^{3} 7$ we believe a barium meal with follow-through and a barium enema are of value in excluding the presence of bowel in the chest, as most of these herniae will contain either small or large intestine, or both ${ }^{189}$ (Table 3). An experienced radiologist's opinion should urgently be sought if there is any clinical suspicion of this condition; in 2 of the patients in this series (Cases 1 and 4) the radiologist was apparently the only one to make the correct diagnosis, but unfortunately only after the patients had died.

It cannot be emphasised too strongly that operative treatment should not be delayed if the diagnosis of a congenital diaphragmatic hernia is made. Bowel strangulation may take place within hours and death can follow quickly and unexpectedly, as happened in Cases 1 and 4.

It is probable that the diagnosis is missed in the older child because the possibility of a congenital diaphragmatic hernia is not considered. Thus it is important, and may be life saving, to include this possibility in the differential diagnosis of any patient with an unusual chest $x$-ray film, particularly if the diaphragm is indefinable and a 'cystic lesion' or an air-fluid level is seen in the left hemithorax.

We thank the consultants who kindly provided the case notes and $x$-rays films, and Professor F Harris for help in the preparation of this manuscript.

\section{References \\ 1 Butler N, Claireaux A E. Congenital diaphragmatic hernia. Lancet 1962; i: 659-63. \\ 2 Kirkland J A. Congenital posterolateral diaphragmatic hernia in the adult. BrJ Surg 1959; 47: 16-22. \\ 3 Bonham Carter $R$ E, Waterston D J, Aberdeen E. Hernia and eventration of the diaphragm in childhood. Lancet 1962; i: 656-9. \\ 4 Synder W H, Greaney E M. Congenital diaphragmatic hernia: 77 consecutive cases. Surgery 1965; 57: 576-88. \\ 5 MacDougall J T, Abbott A C, Goodhand T K. Herniation through congenital diaphragmatic defects in adults. Can J Surg 1963; 6: 301-5. \\ 6 Day B. Late appearance of Bochdalek hernia. Br Med J 1972 ; i: 786. \\ 7 Gross R E. The surgery of infancy and childhood. Philadelphia: Saunders, 1953. \\ 8 Bingham J A W. Herniation through congenital diaphrag- matic defects. BrJ Surg 1959; 47: 1-15. \\ 9 Livaditis A, Nordstrand A. Congenital posterolateral diaphragmatic hernia in infants. Scand J Thorac Cardiovasc Surg 1971; 5: 67-73.}

Correspondence to Dr P W D Meerstadt, 17 Hope Street, Liverpool L1 9BQ

Received 10 December 1979 